\title{
Evaluation Of Textured Concrete As An Alternative For Stone As A Cladding Material
}

\author{
Dr. Mahmoud Ali alsubeh ${ }^{1}$, Dr. Omar Al-Omari ${ }^{2}$, Dr. Wasfi Al-Zgoul ${ }^{3}$ \\ ${ }^{1}$ Assistant Professor, Al-Ahliyyah Amman University \\ ${ }^{2}$ Assistant Professor, Al-Zarqa University ${ }^{3}$ Assistant Professor, Al-Zaytonah University
}

\begin{abstract}
Along with the increasing demand on exterior wall cladding as a protective cover for the interior elements and an indicator for modernity and architectural innovative, comes the need to develop new cladding materials that can replace the old ones and overcome their setbacks. This paper discuss the possibility of replacing stone by textured concrete as a cladding material in order to overcome the main challenges face stone cladding by comparing them together. The comparison was made based on the main requirements of the cladding materials namely; economic, environmental, social, functional and structural aspects.
\end{abstract}

Keywords:Textured concrete; stone; cladding

\section{Introduction}

Recently, buildings of various types have witnessed a dramatic increase in using innovative and dramatic facades as an indication for modernity and development (Mateas and Stern, 2003). In this manner, exterior wall cladding has raised to meet these requirements. Cladding as we may also call it an exterior finishing system is usually implemented to protect the underlying structure and provide a decorative finish. Overall, any cladding material must serve the same idea of providing a high protective covering system (Azevedo, 2011).

According to Gerns (2002), stone cladding is one of the oldest cladding materials for exterior walls, where it has been used for thousands of years and the evidence is still out there in most of the historical buildings. Many reasons were behind choosing this particular material for cladding; for instance, its performance and aesthetics sense attracts both architects and builders toward it (Taylor Maxwell House-The Promenade Clifton, 2013).

In accordance with the evolution in the construction industry, stone facades techniques have been developed either. The alternative and new building systems besides the economic evolution have also an effect on developing new techniques for installing such facades in wide variations of methods (da Costa, 2011). Although stone have great characteristics such as its familiarity for workers, its good compressive strength and aesthetic appearance, it has several limitations (Hoigard and Scheffler, 2007). Its poor tensile strength, probability of decay, high maintenance and cleaning costs and the need for high qualified workforce are some of the reasons that raised the need to find other cladding materials with the same characteristics yet avoid the previously mentioned limitations (Musaağaoğlu, 2005).

According to Edwin and Morris (1966), textured concrete is one of the promising new cladding materials since it has some significant features that qualify it to replace stone. For instance, concrete has natural advantages that will be called upon even more in future, such thermal storage, durability, recyclability, and avoidance of environmental damaging chemicals. In this paper, the economic, environmental, social, functional and structural aspects of each stone and textured concrete cladding will be discussed in order to study the possibility of replacing stone with textured concrete cladding to overcome the setbacks of stone cladding.

\section{Stone Cladding}

Stone cladding uses a thin layer of stone to cover a substrate such as concrete. It is generally preferred for its aesthetic appeal, durability, low maintenance and protective features (Camposinhos, 2014). The limited flexibility, color and workability of limestone have contributed to a variety of wall patterns that reflect the individual style of the owner of a building, the architect, or both. These patterns often maintain a sense of austerity (Azevedo, 2011).

\section{Textured concrete cladding}

Textured Concrete cladding is one of the cladding materials that can be used on both interior and exterior walls. It is basically made of pre-formed concrete (using molds) into the desired panel shapes or into tiles (Edwin and Morris, 1966). If no coloring agents are added, the concrete will appear in grey, but with the addition of colorants, many different colors can be obtained. Stamped textured concrete walls are walls that are provided with a texture stamped on its surface using a technique called the poured concrete technique. Then, the 
concrete is molded in the shapes of stones or masonry patterns instead of smooth panels. The resultant wall can look remarkably like stone or brick, which adds a natural rustic look to the constructed wall. This technique is less expensive and takes less time than those buildings using stone as a cladding material (Taylor, 1992).

\section{Comparison Between Stone Cladding And Textured Concrete Cladding}

The following comparison is based on the main requirements of any building material to perform and deliver the expected results. The following chart shows the main pillars of this comparison, where each aspect is divided into sub-categories that imply for the same subject.

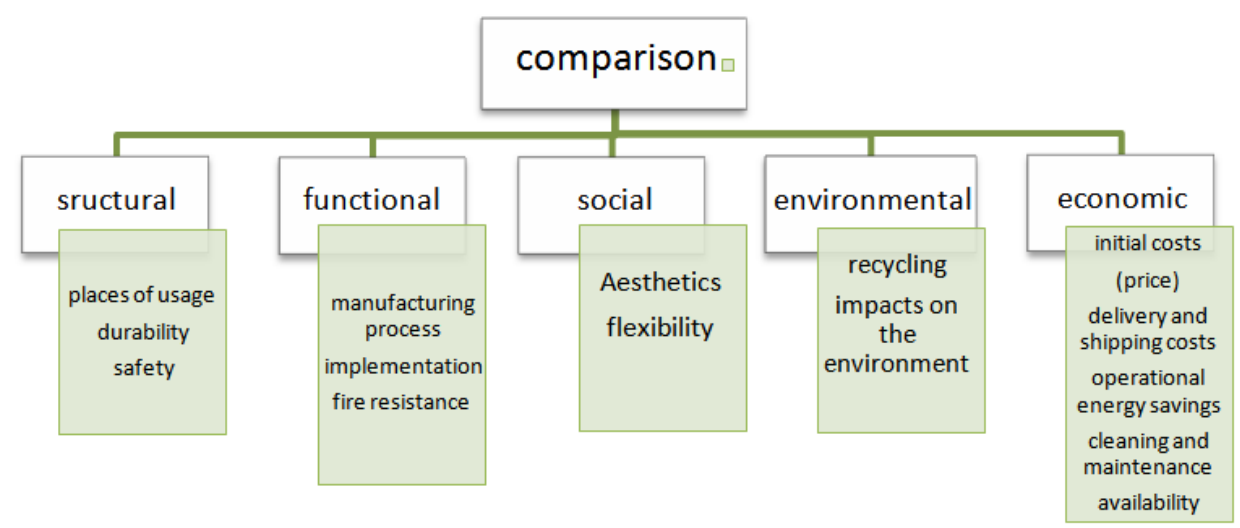

\section{Economic aspect}

The economic feasibility for any construction material is usually calculated by finding the summation of all costs beginning with the purchasing and delivering and ending with disposal. In this paper, the initial cost (price), delivery and shipping costs as well as cleaning and maintenance costs will be calculated for both of stone and texture concrete cladding.

\section{Initial coats}

According to Alibaba (2014), $1 \mathrm{~m} 2$ of natural stone exterior wall cladding panel worth from 10 to 16 US dollars, while I m2 of the exterior wall decorative concrete panel worth from 32.9 to 39.9 US dollars according to the same reference. However, those numbers are vary depending on the country, since stone quarries is limited to a specific areas on the world, which makes using it as a cladding materials in the countries poor with this material a big challenge.

\section{Delivery and Shipping}

Since the rental costs for trucks or any transporting vehicles used in construction sites are based on a multiple factors, the comparison is made on the assumption that the vehicles are sold. For instance, a 60ton stones transporting end dump truck used for shipping natural stones costs about 16,800 to 28,000 US dollars, while a HUAYUDA $8 \mathrm{~m} 3 / 10 \mathrm{~m} 3$ concrete transport mixer truck costs from 50,000 to 70,000 US dollars (Alibaba, 2014).

\section{Operational Energy Savings}

Both stone and concrete stores the energy and release it gradually, which implies on reducing the energy loss and saving the cooling and heating costs. Furthermore, both of them are providing a fine base for installing any insulation material underneath their panels (jgsw-group, 2014).

\section{Cleaning and Maintenance}

For stone, maintenance and cleaning processes include swishing, spraying and coating. For example, the stone spray machine costs about 66,666 to 120,000 US dollars. On the other hand, concrete undergoes under more versatile and complicated processes, according to Alibaba (2014), a concrete wall surface burnishing machine costs from 8,000 to 100,000 US dollars.

Figure 1 below shows a clustered column chart that demonstrates the variations in costs for the stone and textured concrete cladding. 


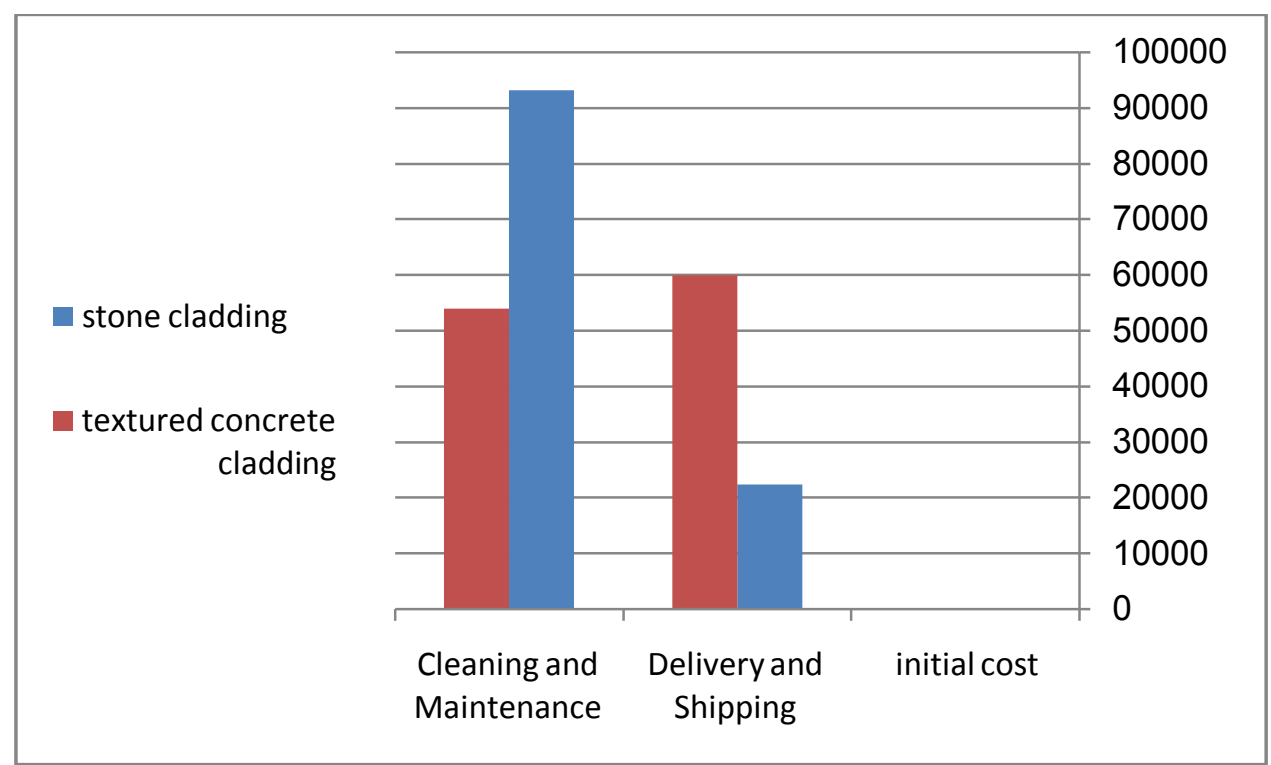

Figure 1: the variations in costs for the stone and textured concrete cladding (Alibaba, 2014)

\section{Availability}

Although some countries have a large number of quarries, other countries don not, see figure 2 below, which shows the main stone quarries in the World. This fact makes stone cladding a double-edged resource, i.e. the previously mentioned costs can be duplicated in countries have a lack of stone quarries. On the other hand, the main elements of the concrete mixture are available in most countries (jgsw-group, 2014).

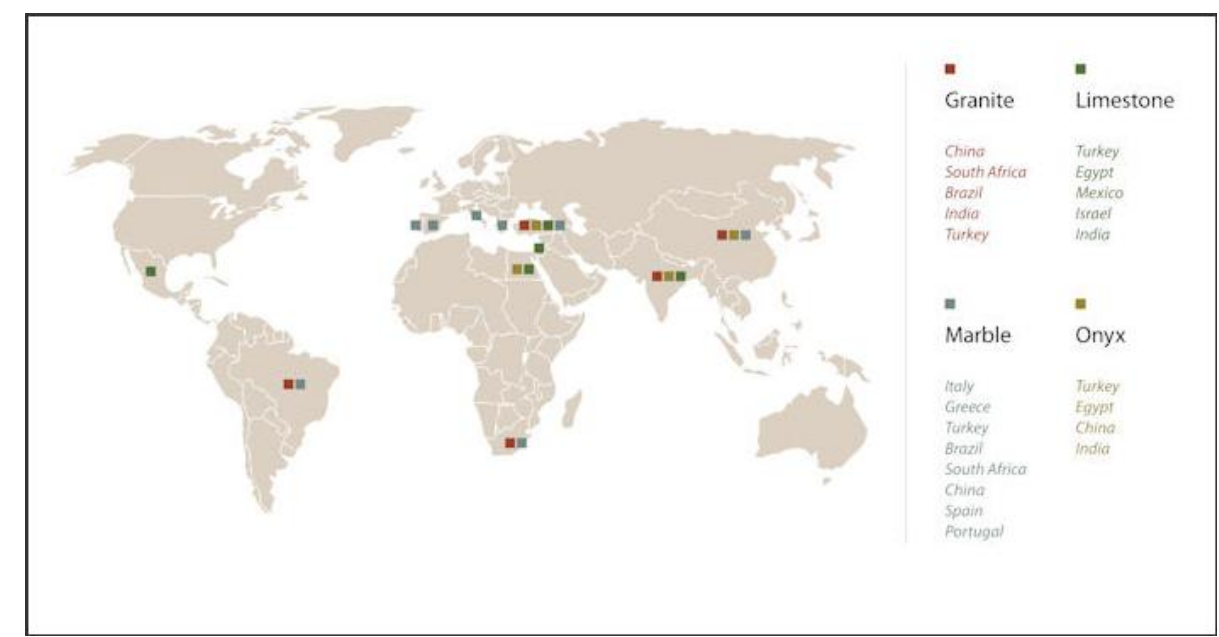

Figure 2: world map quarries (jgsw-group, 2014)

\section{Environmental aspect}

The environmental impact of each material will be discussed in terms of the wastes or pollutants each one produces besides the possibility of recycling and reuse them instead of accumulating in the environment.

\section{Impacts on the environment}

Both stone and concrete have no significant negative impact on the environment since they have the ability to be recycled and manufactured again. However, stone quarries are considered as one of the major sources of pollution threating the ecosystem. Down et al. (1976) mentioned some of the impacts stone quarries have on the environment including; visual intrusion, damage to landscapes, traffic, smoke, noise, dust, damage to caves, loss of land, and a deterioration in water quality. On the other hand, several researches amplified in praising pre-cast concrete as one of the promising sustainable and environmental materials that can replace the in-site cast materials (Sabnis, 2011). 


\section{Recycling}

Both stone and concrete have the ability to be recycled after demolishing, however, the idea here is to find the easier yet more functional material to be reused in construction of buildings. Generally, stone is a durable material that is hardly affected by demolishing or any destructive forces. So, most of the stones found in demolished sites are re-used in the shape that it were found in. on the other hand, concrete is collected from demolished sites in a completely different form, where it requires crushing, water flotation separating, handpicking and many other necessary processes to qualify it to be used again (Limbachiya and Roberts, 2004).

\section{Social aspect}

The social aspect is related to the acceptance of users or surrounding people to the construction material, for instance, the aesthetics of the buildings and its flexibility on design are some of the indicators that are used to measure this acceptance.

\section{Aesthetics}

Aesthetics can be evaluated due to several aspects including; color, elegancy and hierarchy. Figure 3 below shows two buildings facades, the right one used stone as a cladding material and while the second one used textured concrete (left building).
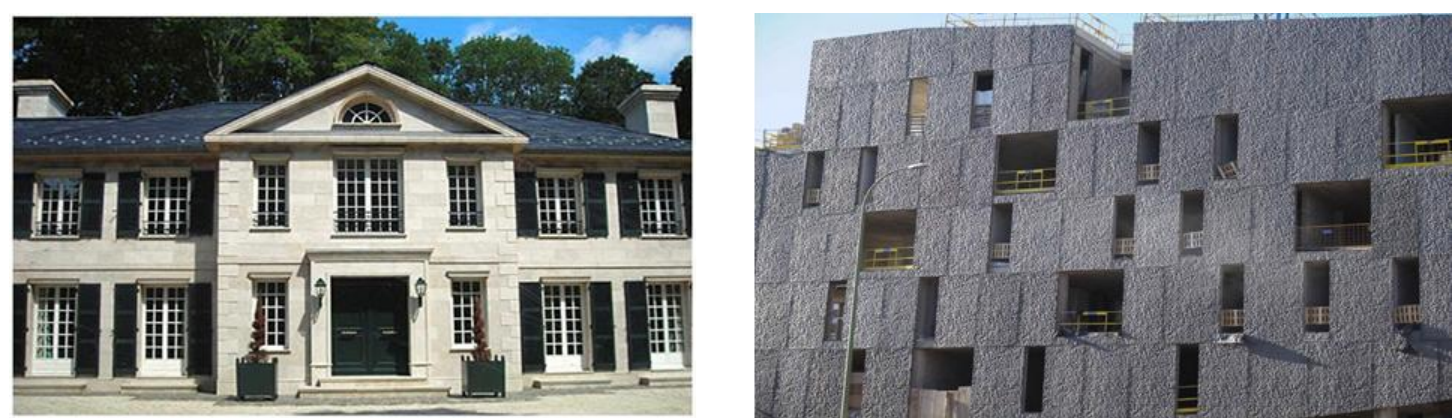

Figure3: (Left) stone exterior cladding (ArchiExpo, 2014); (Right) textured concrete exterior cladding (Architectonic Concrete, S.L., 2011)

Stone is a little bit limited with the white colour and its grades, whereas colorants can be added to concrete to change its grey colour. Stone has the most elegant look of all materials, its unique protrusions creates this prestigious appearance (Gerns, 2002).

\section{Flexibility}

Although stone is found now in many complicated and different shapes, the hard nature of stone hardens and restricts this formulation unlike the concrete panels which requires further less efforts, costs and time to be formulated. The high flexibility of concrete enlarges the design possibilities range to meet the different tastes and design approaches (Azevedo, 2011; Edwin and Morris, 1966).

\section{Functional aspect \\ Manufacturing Process}

At first, the stone is cutting out from the mountains or whenever it is to move it into the nearest quarries. The shifted stone from quarries for cladding have to be thin enough, so a more complicated cutting process is applied into them. The cut stones are transferred using large tankers into the site (Costa, 2011). On the other hand, textured concrete can be manufactured in the site by mixing natural sand with colour sand and adhesives all with white cement making a mixture in a powder form. Sometimes precast concrete blocks are moved into the site for cladding.

\section{Implementation}

Usually, stone cladding is installed with an assistant of several lightweight substrates including; mortar scratch coat, expanded metal mesh, fiber cement sheet, water-proof barrier and the timber stud frame besides the mortar mix, which is used for fixing the stone panels on the wall. For the corners, metal corners are used too. Where concrete cladding is installed after a face of coarse plasterer and placed on layers (Donaldson, 1991). 


\section{Fire Resistance}

Stone is considered as one of the fire resistance construction materials due to its nature, where it is a bad heat conductor. Concrete is a good fire resistance due to its behavior in case of fire, however, this behavior depends on the used cement and aggregates (Hoigard and Scheffler, 2007).

\section{Structural aspect \\ Places of Usage}

Stone can be used in both interior and exterior walls cladding besides floors. Concrete has the same usage places yet it can be used also on ceilings.

\section{Durability}

Stone as known is the most durable construction material that has been ever used; its toughness is presented by its resistance to mould, impacts, water and fire (Gerns, 2002). Concrete durability, on the other hand, depends on several factors including; the cement content, compaction and curing as well as its cover and permeability (Mays, 2002).

\section{Safety}

As for stone cladding, most of the attention of the designers is focused toward preventing failure of the connections of stone cladding. In this manner, the stone panel's flexural behavior under the wind load is studied extensively in order to find the minimum thickness of the stone panels that has to be used. On the other hand, concrete undergoes under several failures including, cracking, thermal expansion, deflection, etc. however, these failures can be avoided by mixing the appropriate amounts of the concrete elements and using the suitable admixtures (Hoigard and Scheffler, 2007).

\section{Results AndDisscussion}

Based on the previous analysis of the main aspects, each aspect will be evaluated taking into consideration whether each aspect has a positive or negative impact on the performance of the building. The following table shows the evaluation of the economic, environmental, social, functional and structural aspects of each stone and textured concrete cladding.

Table 1: comparison between the impacts of both stone and textured concrete cladding

\begin{tabular}{|c|c|c|c|}
\hline Comparison aspect & Sub-categories & Stone cladding & $\begin{array}{c}\text { Textured concrete } \\
\text { cladding }\end{array}$ \\
\hline \multirow{5}{*}{ 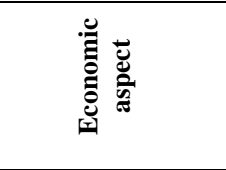 } & Initial costs (price) & Negative & Positive \\
\hline & Delivery and shipping costs & Positive & Negative \\
\hline & Operational energy savings & Positive & Positive \\
\hline & Cleaning and maintenance & Negative & Positive \\
\hline & Availability & Negative & Positive \\
\hline \multirow[b]{2}{*}{ 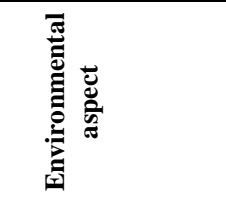 } & Impacts on the environment & Negative & Positive \\
\hline & Recycling & Positive & Negative \\
\hline \multirow{2}{*}{ 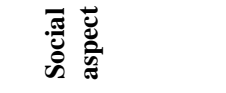 } & Aesthetics & Positive & Positive \\
\hline & flexibility & Negative & Positive \\
\hline \multirow{3}{*}{ 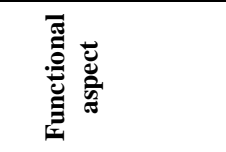 } & manufacturing process & Negative & Positive \\
\hline & implementation & Negative & Positive \\
\hline & fire resistance & Positive & Positive \\
\hline \multirow{3}{*}{ 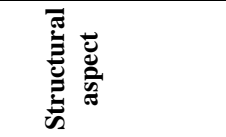 } & places of usage & Positive & Positive \\
\hline & durability & Positive & Negative \\
\hline & safety & Negative & Negative \\
\hline
\end{tabular}

As can be seen from table 1 above, textured concrete cladding does better in what concerning availability, initial prices, cleaning and maintenance costs, impact on the environment, flexibility, manufacturing process and implementation. On the other hand, stone cladding discriminate on its ability to be recycled, the required shipping costs and durability. However, some characteristics have the same impact for both stone and concrete such as safety, fire resistance, places of usage, the operational energy savings and their positive effect 
of aesthetics. As a result, despite the negative effects it has, textured concrete cladding have a considerable positive effects makes it a strong competitive for stone as a cladding material.

\section{Conclusions and Recommendations}

Stone is one of the oldest exterior wall cladding materials that ever used, however, this material faced and still facing some challenges including its unavailability in most of the countries around the world, which increase its cots in those areas, besides the bad effect of stone quarries on the environment. Also, the hardness of stone making it's manufacturing a complicated process and limits its flexibility to be shaped on different shapes, taking into consideration the complicated implementing process and maintenance process.

Although textured concrete has some problems including; poor durability and a high delivery costs, it succeed to overcome most of the challenges facing stone cladding such as; availability, low initial prices, low cleaning and maintenance costs, positive impact on the environment, high flexibility, easier manufacturing process and implementation. Summary of speech, textured concrete cladding can successfully replace stone cladding in regular circumstances.

\section{Recommendations}

Based on the previous analysis, the following are some recommendations that can be followed when using textured concrete cladding in order to enhance its performance:

Using of precast concrete can add an advantage regarding both environmental and economic aspects Some of the problems facing concrete can be override by adding the proper admixtures

Using the trained and professional labor in implementing cladding can help in overcome most of the expected setbacks

Further studies regarding textured concrete and the way it has been used in new and more modern ways is recommended to be conducted

\section{References}

[1]. Alibaba., (2014). cost estimation. [Online]. Available at $<$ http://www.alibaba.com/ $>$, accessed at $2^{\text {nd }}$ October, 2014

[2]. ArchiExpo, (2014).Natural stone facade cladding.[Online]. Available at<http://www.archiexpo.com/prod/indiana-limestonecompany/natural-stone-facade-cladding-59284-468452.html>, accessed at 2nd October, 2014

[3]. Architectonic Concrete, S.L., (2011).Textured building's façade.Las Palmas de Gran Canaria. Spain.[Online]. Available at <http://xavier-architectonic.blogspot.com/2011/09/textured-buildings-facade-las-palmas-de.html>, accessed at $2^{\text {nd }}$ October, 2014

[4]. Azevedo, C.R.F., (2011). Selection of fuel cladding material for nuclear fission reactors. Engineering Failure Analysis, 18 (8), 19431962

[5]. da Costa, M., (2011). Quality Control Manual for Stone Cladding Facades. M.Sc. Thesis Extended Abstract

[6]. de Camposinhos , R., (2014). Stone Cladding Engineering. springer, 2014 Edition

[7]. Donaldson, B., (1991). Exterior Wall Systems: Glass and Concrete Technology, Design, and Construction. ASTM International, 1991 Edition

[8]. Down, C. G., Stocks, J., and Pryor, R. N.,(1976). The environmental impact of large stone quarries and open-pit non-ferrous metal mines in Britain. Royal School of Mines, Imperial College, 1976 Edition

[9]. Edwin, A., and Morris, J., (1966). Precast-concrete cladding. Fountain P. 1966 Edition

[10]. Gerns, E. A., (2002). design issues for thin-stone cladding systems. RCI Symposium of Building Envelope Technology in Coral Springs, Florida.

[11]. Ghavami, K., Universidade, P., and do Rio C., (1984). Low-cost and energy saving construction materials. Envo Pub. Co.1984 Edition

[12]. Hoigard, K. R., and Scheffler, M. J., (2007). Dimension Stone Use in Building Construction. ASTM International, 2007 Edition

[13]. jgsw-group., (2014). world map- quarries. [Online]. Available at <http://www.jgsw-group.com/World-Map-Quarries.html>, accessed at $2^{\text {nd }}$ October, 2014

[14]. Limbachiya, M. C., and Roberts, J. J.,(2004). Construction Demolition Waste. Thomas Telford, 2004 Edition

[15]. Mateas, M. and Stern, A., (2003). Architecture idioms and early observations of the interactive drama façade. School of Computer Science, Carnegie Mellon University, Pittsburgh

[16]. Mays , G.C., (2002). Durability of Concrete Structures: Investigation, repair, protection. CRC Press, 2002 Edition

[17]. Musaağaoğlu, B. O., (2005). Performance of the Stone Building Envelope: Cladding to Curtain Wall. Thesis, the Graduate School of Natural and Applied Sciences of Middle East Technical University

[18]. Sabnis, G. M., (2011). Green Building with Concrete: Sustainable Design and Construction. CRC Press, 2011 Edition

[19]. Taylor Maxwell House-The Promenade Clifton., (2013). naturally TM an innovative natural stone cladding system. taylormaxwell

[20]. Taylor, H. P. J., (1992). Precast Concrete Cladding. Halsted Pr , 1992 Edition 